\title{
Composition and Epigenetic Markers of Heterochromatin in the Aphid Aphis nerii (Hemiptera: Aphididae)
}

\author{
M. Mandriolia ${ }^{\mathrm{a}}$ P. Azzoni ${ }^{\mathrm{b}} \quad$ G. Lombardo ${ }^{\mathrm{a}} \quad$ G.C. Manicardi ${ }^{\mathrm{C}}$ \\ ${ }^{a}$ Dipartimento di Biologia $\mathrm{e}^{\mathrm{b}}$ Dipartimento di Medicine e Specialità Mediche, Università di Modena e \\ Reggio Emilia, Modena, e ${ }^{C}$ Dipartimento di Scienze Agrarie e degli Alimenti, Università di Modena e \\ Reggio Emilia, Reggio Emilia, Italia
}

\section{Key Words}

Aphid - Epigenetics · Heterochromatin · Holocentric

chromosomes $\cdot$ Satellite DNA

\begin{abstract}
A detailed karyotype analysis of the oleander aphid Aphis nerii focusing on the distribution, molecular composition and epigenetic modifications of heterochromatin was done in order to better understand the structure and evolution of holocentric/holokinetic chromosomes in aphids. The female karyotype $(2 n=8)$ consisted of 3 pairs of autosomes and a pair of $X$ chromosomes that were the longest elements in the karyotype and carried a single, terminally located nucleolar organizer region. Males showed $2 \mathrm{n}=7$ chromosomes due to the presence of a single $X$ chromosome. Heterochromatin was located in the $X$ chromosomes only and consisted of 4 satellite DNAs that have been identified. A. nerii constitutive heterochromatin was enriched in mono-, di- and trimethylated $\mathrm{H} 3$ histones and HP1 proteins but, interestingly, it lacked DNA methylation that was widespread in euchromatic chromosomal regions. These results suggest that aphid heterochromatin is assembled and condensed without any involvement of DNA methylation.
\end{abstract}

Copyright $\odot 2011$ S. Karger AG, Basel (c) 2011 S. Karger AG, Basel

$1424-8581 / 11 / 1331-0067 \$ 38.00 / 0$

Fax +41613061234

E-Mail karger@karger.ch

www.karger.com
Accessible online at: www.karger.com/cgr
Holocentric/holokinetic chromosomes show centromeric activity spread along the whole chromosomal axis so that at anaphase chromatids move apart in parallel and do not form the classical V-shaped figures typically observed in monocentric chromosomes [Hughes-Schrader and Schrader, 1961; Blackman, 1987]. They have been described in almost all the higher eukaryote taxa so far studied, with the exception of echinoderms and chordates and they are present in each principal node of the eukaryote phylogenetic tree [Wrensch et al., 1994; Dernburg, 2001; Manicardi et al., 2002].

Even though aphids are extremely useful for the study of holocentric/holokinetic chromosomes in view of the ease mitotic chromosomes are obtained from their embryonic tissues, until now their chromosomes have not been deeply studied [Bizzaro et al., 1996, 2000; Mandrioli et al., 1999a, b; Manicardi et al., 2002; Mandrioli and Borsatti, 2007; Criniti et al., 2009]. Moreover, the relationship between their chromatin structure and epigenetics has been just lightly touched upon [Mandrioli and Borsatti, 2007] making aphids effectively uncharted biological models for epigenetic studies. At the same time, a cytogenetic analysis of aphids is very helpful since the description of species-specific chromosomal markers could make easier the identification of species that is, 
at present, quite difficult [Blackman, 1980; Rakauskas, 1998].

Aphid karyotypes are frequently described in the literature as highly variable in view of the holocentric/ holokinetic nature of their chromosomes which stabilize rearrangements and fragmentations [Blackman, 1980; Blackman et al., 2000]. Surprisingly, the species of the genus Aphis present a very stable chromosome number, as observed in A. gossypii, A. verbasci, A. spiraecola, A. affinis, A. clematidis, A. sambuci, A. pomi, A. solanella and A. fabae [Khuda-Bukhsh and Pal, 1985; Manicardi et al., 1998a, b; Criniti et al., 2005; Rivi et al., 2009] making this taxon intriguing in terms of karyotype constancy.

In the present paper, a detailed cytogenetic analysis of the oleander aphid Aphis nerii has been done allowing us to identify and localize on chromosome 4 satellite DNAs that constitute $A$. nerii heterochromatin. Moreover, the species specificity of $A$. nerii satellite DNAs has been evaluated in Aphis gossypii and Aphis spiraecola by dot blotting, whilst the epigenetic state of $A$. nerii heterochromatin has been studied by looking for the presence of DNA methylation, $\mathrm{H} 3$ histone methylation at lysine 9 and heterochromatic protein 1 (HP1). Lastly, other repetitive DNAs and multigenic DNA families (including telomeric sequences and $28 \mathrm{~S}$ and $5 \mathrm{~S}$ ribosomal DNA genes) have been identified and localized on chromosomes.

\section{Material and Methods}

Specimens of $A$. nerii were collected in Modena (Italy) and maintained at $22^{\circ} \mathrm{C}$ with $16: 8 \mathrm{~h}$ light/darkness on Hoya carnosa plants. Male aphids were obtained by exposing parthenogenetic females to short photoperiods (8:16 h light/darkness) according to Crema [1979]. A. gossypii and A. spiraecola were collected on $\mathrm{Hi}$ biscus sp. plants in Modena (Italy).

Chromosome preparations were made from parthenogenetic female embryos by spreading as previously described [Mandrioli et al., 1999a]. Male chromosomes have been obtained by squash preparation of single embryos as reported by Manicardi et al. [1991].

C-banding treatment was performed according to Sumner [1972]. After treatment, slides were stained with chromomycin $A_{3}$ $\left(\mathrm{CMA}_{3}\right)$ according to Schweizer [1976] and with 4,6-diamidino2-phenylindole (DAPI), as described by Donlon and Magenis [1983]. Silver staining was performed according to Manicardi et al. [1998a].

In situ nick translation (NT) experiments were done on fresh chromosome spreads digested with $0.6 \mathrm{U} / \mu \mathrm{l}$ of the endonucleases in the supplier's buffer for $1 \mathrm{~h}$ at $37^{\circ} \mathrm{C}$. NT was carried out for 30 min according to Sumner et al. [1990], except that extravidinFITC was used as a label, in place of streptavidin alkaline phosphatase, to reveal the incorporation of biotin-dUTP.

In situ immune-staining experiments were performed with a mouse anti-Drosophila melanogaster HP1a antibody diluted
1:500 (kindly provided by Rebecca Kellum) [Huang et al., 1998], with rabbit antibodies against mono- and di-methylated-K9 histone H3 (Me9H3) (Upstate, Cambridge, UK) and with rabbit antitri-methylated-K9 histone $\mathrm{H} 3$ (Me9H3) (Active Motif, Carlsbad, Calif., USA) diluted 1:250 according to Bongiorni et al. [2001].

In situ immuno-detection of 5-methylcytosine residues was performed using a mouse anti-5-methylcytosine monoclonal antibody (Epigentek Inc., Brooklyn, N.Y., USA) following the protocol reported in Pfarr et al. [2005].

Random priming probe digoxigenin-labeling was performed according to the Roche protocol, whereas fluorescent in situ hybridization (FISH) was done according to Mandrioli et al. [1999a].

The presence of the telomeric (TTAGG) $)_{n}$ repeat has been evaluated in $A$. nerii by in situ hybridization with a telomeric probe obtained by PCR amplification using the 2 primers F (TTAGG) and $\mathrm{R}(\mathrm{CCTAA})_{5}$ in the absence of template, as described by Ijdo et al. [1991].

Immuno-fluorescent preparations and FISH slides were observed using a Zeiss Axioplan epifluorescence microscope equipped with a $100 \mathrm{~W}$ mercury light source. Photographs of the fluorescent images were taken using a CCD camera (Spot, Digital Instrument, Madison, Wisc., USA) and using the Spot software supplied with the camera and processed using Adobe Photoshop (Adobe Systems, Mountain View, Calif., USA).

DNA extraction followed a standard phenol-chloroform protocol [Mandrioli et al., 1999a], whilst Southern blot hybridization, cloning and restriction enzyme digestion were done as described in Bizzaro et al. [2000]. SatDNA clones have been sequenced at BMR Genomics, whereas sequence alignments and search for internal repeats were done using the GCG software (GCG Computer Group, Madison, Wisc., USA). The curvature-propensity plot was calculated with DNase I parameters of the bend.it server (http://www2.icgeb.trieste.it/ dna/bend_it.html) according to Gabrielian et al. [1996].

RNA extraction and reverse-transcription PCR (RT-PCR) were performed with the SV Total RNA Isolation System (Promega Corporation, Madison, Wisc., USA) and the Access RT-PCR System (Promega), respectively, according to the supplier's protocols.

The $\beta$-tubulin gene was amplified using the primers $\mathrm{F}_{\mathrm{TUB}}$ (5'ACTAGCATAGCAATTCGG) and $\mathrm{R}_{\mathrm{TUB}}$ (5'GCCTTGACCATTACGGACG). Amplification served us as positive control for RNA samples in RT-PCR experiments.

The 28S rDNA probe was obtained by PCR amplification of a $400 \mathrm{bp}$ fragment of the $28 \mathrm{~S}$ rDNA gene using the 2 primers, $\mathrm{F}$ (5'AACAAACAACCGATACGTTCCG) and R (5'CTCTGTCCGTTTACAACCGAGC), designed according to the insect $28 \mathrm{~S}$ rRNA sequences available in GenBank. The amplification mix contained $100 \mathrm{ng}$ genomic DNA, $1 \mu \mathrm{M}$ of each primer, $200 \mu \mathrm{M}$ dNTPs and $2 \mathrm{U}$ of DyNAZyme II polymerase (Finnzymes Oy). Amplification was performed using a Hybaid thermal-cycler at an annealing temperature of $60^{\circ} \mathrm{C}$ for $1 \mathrm{~min}$ with an extension time of $1 \mathrm{~min}$ at $72^{\circ} \mathrm{C}$.

The $5 \mathrm{~S}$ rDNA repeat unit of $A$. nerii was amplified by PCR using 2 primers, F (5'TGCACGTAGTGTTCCCAAGC) and R (5'ACGACCATACCACGTTGAATAC), derived from the insect $5 \mathrm{~S}$ rRNA sequences available in GenBank. The 2 primers were designed so that primer cross-hybridization with other pol IIIcontrolled genes was prevented [Geiduschek and TocchiniValentini, 1988]. The amplification mix contained $100 \mathrm{ng}$ ge- 
nomic DNA, $1 \mu \mathrm{M}$ of each primer, $200 \mu \mathrm{M}$ dNTPs and $2 \mathrm{U}$ of DyNAZyme II polymerase (Finnzymes Oy). Amplification was performed as above except that the annealing temperature was $59^{\circ} \mathrm{C}$ for $30 \mathrm{~s}$ and the extension time $45 \mathrm{~s}$ at $72^{\circ} \mathrm{C}$.

\section{Results}

According to DAPI, $\mathrm{CMA}_{3}$ and silver staining (fig. 1AC), A. nerii female karyotype consists of 8 chromosomes including 6 autosomes and $2 \mathrm{X}$ chromosomes, easily identified as they are usually the longest chromosomes and bear the unique nucleolar organizing regions (NORs) [Manicardi et al., 2002]. To confirm X chromosome identification, the male karyotype was examined evidencing 7 autosomes and only one NOR-bearing X chromosome (fig. 1D-F).

For a detailed analysis of the A. nerii karyotype, we performed C-banding followed by DAPI staining showing large AT-rich heterochromatic regions at one telomere and in 5 intercalary bands of the $\mathrm{X}$ chromosomes (fig. 1G). No heterochromatic bands were detected in the autosomes (fig. 1G, Q).

$\mathrm{CMA}_{3}$-stained mitotic metaphases showed a single GC-rich heterochromatic region located at one telomere of both X chromosomes (fig. $1 \mathrm{H}$ ) indicating that most of the aphid heterochromatin is AT-rich. This GC-rich band was highly positive after silver staining (fig. 1I) and FISH carried out with the $28 \mathrm{~S}$ rDNA probe (fig. 1L) assessing that it corresponds to NOR-containing actively transcribed rDNA genes.

The chromosomal localization of 5S rDNA genes revealed a single hybridization interstitial signal located in autosome pair 1 (fig. $1 \mathrm{M}$ ), as deduced by the silver staining of the same metaphase plate (fig. $1 \mathrm{~N}$ ).

FISH experiments with the (TTAGG) ${ }_{n}$ telomeric probe revealed bright signals at each telomere of all chromosomes, whilst no interstitial signals were detected (fig. 1O).

The composition of heterochromatin was studied by the digestion of $A$. nerii genomic DNA with 30 endonucleases (MspI, HpaII, BamHI, ScaI, XmaI, SmaI, AvaI, MboI, SacI, SacII, DraI, BglI, SphI, FokI, RsaI, CfoI, KpnI, AluI, EcoRI, NotI, SalI, HhaI, XbaI, EcoRV, ApaI, NdeI, HaeIII, HinfI, PstI and ScaI) searching for satellite DNAs that are generally common components of constitutive heterochromatin. Four restriction enzymes (MboI, RsaI, EcoRI and $A l u \mathrm{I}$ ) showed electrophoretic band ladders that are a typical feature of clustered satellite DNAs.

Monomeric fragments of the MboI, RsaI, EcoRI and AluI ladders have been used as hybridization probes in
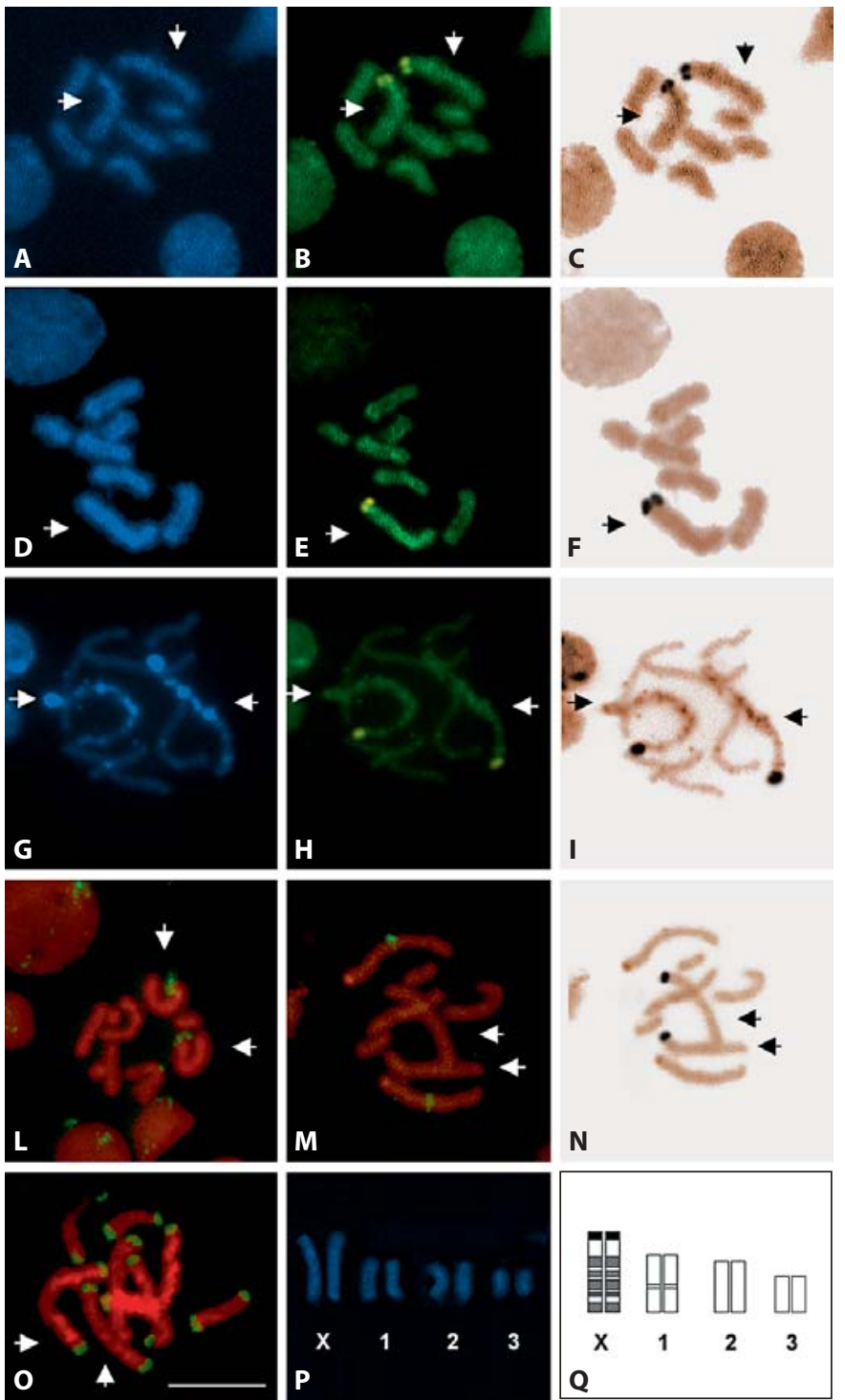

Fig. 1. Mitotic chromosomes of Aphis nerii: DAPI (blue) (A, D), $\mathrm{CMA}_{3}$ (yellow-green) (B, E) and silver staining (C, F, P) of A. nerii female (A-C, P) and male (D-F) unbanded chromosomes. DAPI (G), $\mathrm{CMA}_{3}(\mathbf{H})$ and silver staining (I) of female chromosomes after C-banding. FISH with fluorescein-labeled (green) 28S rDNA (L), $5 \mathrm{~S}$ rDNA $(\mathbf{M})$ and telomeric probes $(\mathbf{N})$ on $A$. nerii female chromosomes stained with propidium iodide (red). DAPI-stained karyotype (0) and karyogram (Q) showing the distribution of GC-rich heterochromatin/NORs (black band), AT-rich heterochromatin (dark gray) and $5 \mathrm{~S}$ cluster (light gray) of $A$. nerii. Arrows indicate $\mathrm{X}$ chromosomes. Bar corresponds to $10 \mu \mathrm{m}$.

Southern blotting experiments showing a regular ladder of multimers of basic length, which is typical of clustered satellite DNA confirming that these restriction enzymes isolated highly repeated and clustered DNA sequences (fig. 2A-D). 

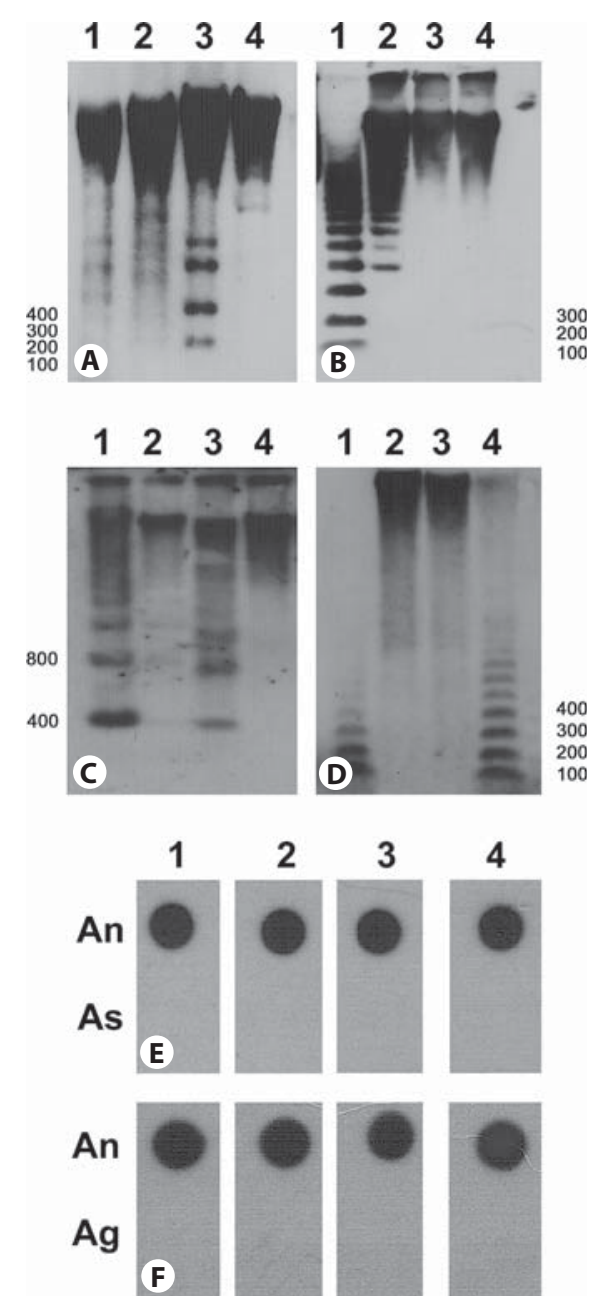

Fig. 2. Southern blotting with the AluSAT (A), RsaSAT (B), EcoSAT (C) and MboSAT (D) probes showed that these sequences are highly repeated and clustered in A. nerii genome. A Digestion of A. nerii genomic DNA with KpnI (1), HindIII (2), AluI (3) and ScaI (4) and hybridized with the AluSAT probe. B Digestion of A. nerii genomic DNA with RsaI (1), HindIII (2), AluI (3) and ScaI (4) and hybridized with the RsaSAT probe. C Digestion of $A$. nerii genomic DNA with EcoRI (1), ScaI (2), NotI (3) and SalI (4) and hybridized with the EcoSAT probe. D Digestion of $A$. nerii genomic DNA with Sau3A (1), SalI (2), ScaI (3) and MboI (4) and hybridized with the MboSAT probe. E, F Dot blot experiments have been performed in order to verify the species specificity of $A$. nerii (An) satellites showing that AluSAT (1), RsaSAT (2), EcoSAT (3) and RsaSAT (4) are not present in A. spiraecola (As, E) nor in A. gossypii (Ag, F) genomes. Molecular weight is indicated near each blot in panels (A-D).
Both in situ nick translation, performed after digestion of chromosomes with the endonucleases (fig. 3A, D, $\mathrm{G}, \mathrm{L}$ ), and in situ hybridization using the satellite DNAs as probes (fig. 3C, F, I, N) showed that the 4 highly repeated sequences co-localized with heterochromatic areas located in the $\mathrm{X}$ chromosomes, whilst no signals were detected on autosomes. In particular, MboSAT showed a bright labelling of the heterochromatic AT-rich telomere and in some of the interstitial heterochromatic bands of the $\mathrm{X}$ chromosomes (fig. 3A-C). EcoSAT was mainly located in a single intercalary heterochromatic band (fig. 3D-F), whereas both AluSAT (fig. 3G-I) and RsaSAT (fig. 3L-N) were present in all the heterochromatic bands of the $A$. nerii X chromosomes.

Dot blotting in 2 other aphids (A. gossypii and A. spiraecola) indicated that the $4 A$. nerii satellite DNAs were not present in these 2 co-generic species (fig. 2E-F).

A. nerii satDNAs have been cloned (fig. 4) and 5 clones sequenced for each satellite DNA (table 1). Bioinformatic analyses showed that all the satDNAs presented conserved sequences whose similarities ranged from 93 to $100 \%$ (table 1). The 4 satellite DNAs presented a high AT content (from 60.1 to $66.4 \%$ ) with the only differences due to nucleotide mutations, whereas no sequence rearrangements were detected. A search for homology with other DNA sequences in GenBank and EMBL databases yielded no significant results with all 4 satDNA consensus sequences. Similarly, no significant direct or inverted repeats were found.

The curvature-propensity plot, calculated with the DNase I parameters of the bend.it server, clearly showed that the 4 satDNAs presented at least one region with a high curvature propensity value, whose magnitude roughly corresponds to the value calculated for a highly curved motif described in a DNA satellite of the pigeon Columba risoria (GenBank ID: CRBENSAT).

A transcription assay, carried out by RT-PCR together with the $\beta$-tubulin gene (utilized in order to confirm both the presence and integrity of the mRNAs), did not give any product suggesting that the 4 satellite DNAs were not transcribed in $A$. nerii (data not shown).

In order to further characterize the A. nerii heterochromatin, we also verified the presence of HP1 proteins, methylated $\mathrm{H} 3$ histones and methylcytosine residues. In situ immuno-detection clearly indicated that HP1 proteins were not scattered along all $A$. nerii chromosomes, but mainly located on both $\mathrm{X}$ chromosomes which showed several bands that overlap with heterochromatic regions (fig. 5A). The same heterochromatic areas were also labeled with antibodies against mono-, di- and tri- 
Fig. 3. Localization of the $4 \mathrm{~A}$. nerii satellite DNAs evaluated by in situ nick translation carried out after digestion of chromosomes with the endonucleases $M b o I$ (A), $E c o$ RI (D), AluI (G) and RsaI (L); fluorescence in situ hybridization using MboSAT (C), EcoSAT (F), AluSAT (I) and RsaSAT (N) as fluorescein-labeled probes (green) on A. nerii female chromosomes stained with propidium iodide (red). The identification of $\mathrm{X}$ chromosomes has been performed using silver staining $(\mathbf{B}, \mathbf{E}, \mathbf{H}, \mathbf{M})$. Arrows indicate X chromosomes. Bar corresponds to $10 \mu \mathrm{m}$.
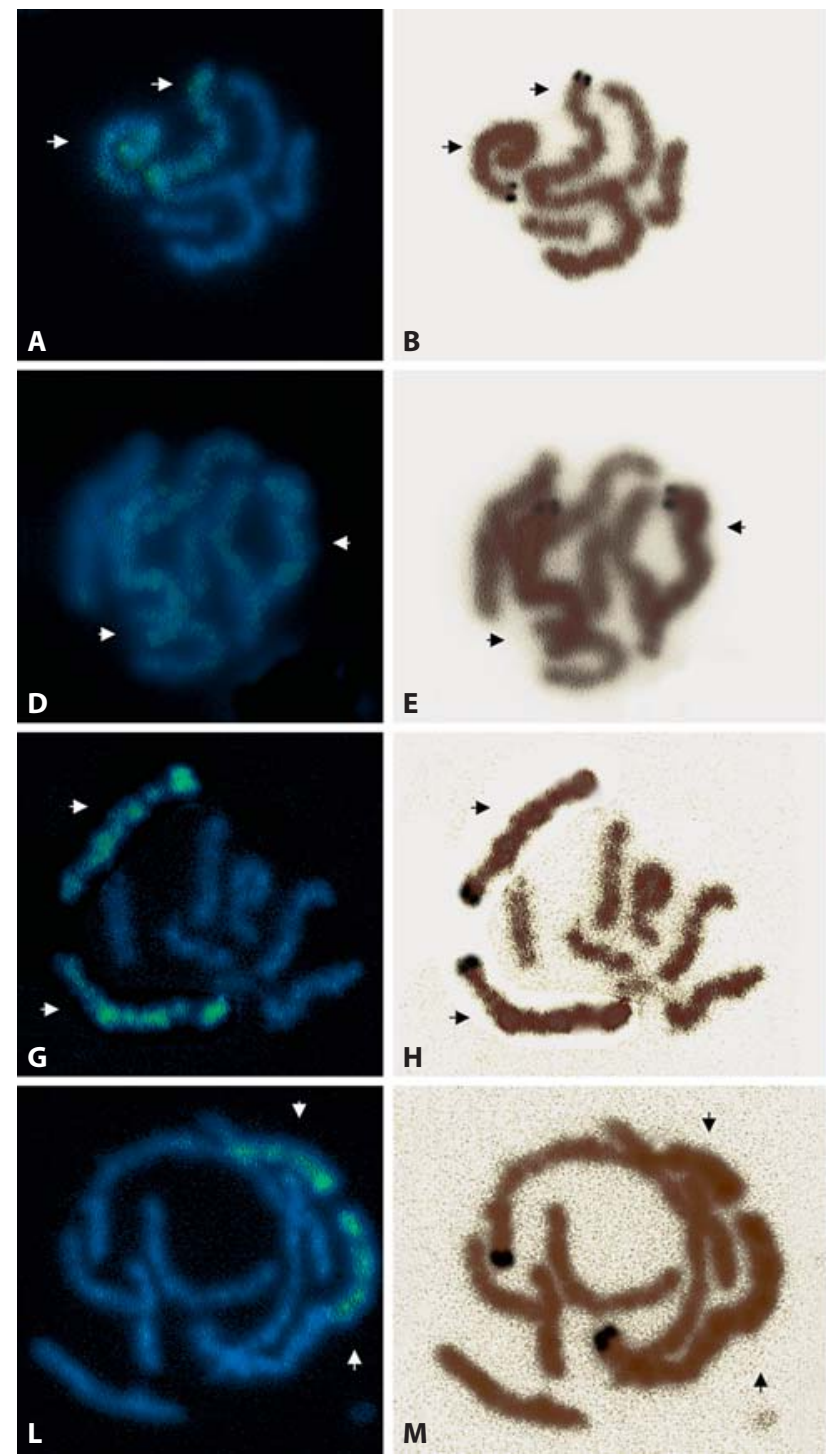
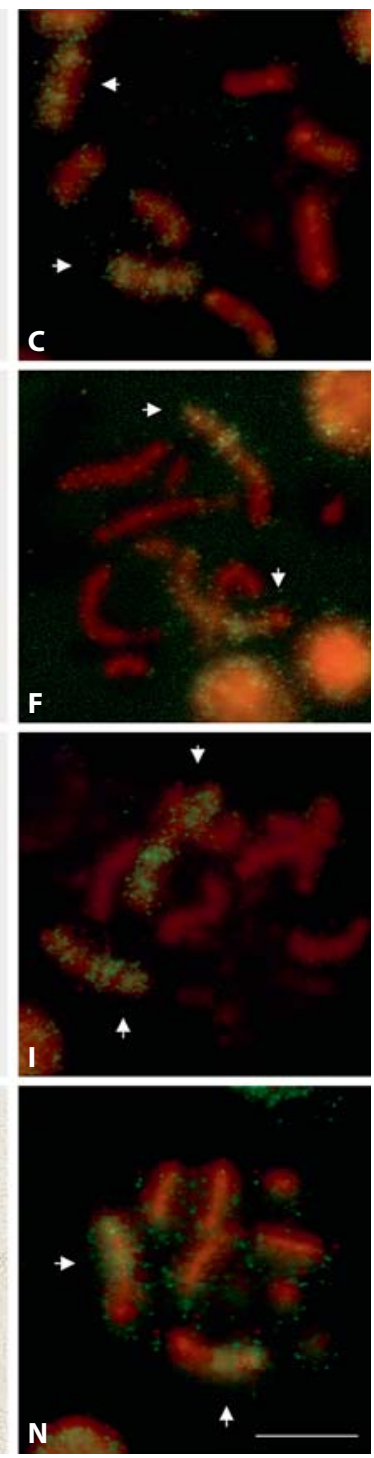

Table 1. Sequence analysis of the four satDNAs of $A$. nerii

\begin{tabular}{llllllll}
\hline SatDNA & Length & $\begin{array}{l}\text { Sequence } \\
\text { similarity }\end{array}$ & $\begin{array}{l}\text { AT con- } \\
\text { tent }\end{array}$ & $\begin{array}{l}\text { Curvature } \\
\text { propensity }\end{array}$ & $\begin{array}{l}\text { Curved } \\
\text { region }\end{array}$ & $\begin{array}{l}\text { Similarity in } \\
\text { databases }\end{array}$ & $\begin{array}{l}\text { Sequence ID in } \\
\text { GenBank }\end{array}$ \\
\hline EcoSAT & $406 \mathrm{bp}$ & $96-100 \%$ & $60.1 \%$ & yes & $100-150$ & none & HM467647 \\
AluSAT & $198 \mathrm{bp}$ & $95-99 \%$ & $63.6 \%$ & yes & $50-100$ & none & nM467648 \\
RsaSAT & $164 \mathrm{bp}$ & $95-100 \%$ & $66.4 \%$ & yes & $85-50 / 55-75 /$ & HM467649 \\
MboSAT & $107 \mathrm{bp}$ & $93-99 \%$ & $64.4 \%$ & yes & $65-105$ & none & HM467650
\end{tabular}

The analysis of the four satDNAs of $A$. nerii allowed to determine the length of the consensus sequence, the variability in sequence for each satDNA, the AT content, the curvature propensity, the localization of the curved satDNA portion in each sequence, the presence of similar sequence in GenBank and EMBL and the ID of the satDNA consensus sequences. 


\section{EcosAT}

GGAAAAACGTTGTTCGCCTTCCTAGTCTGGAGCCTCAGTAGTTCTCAA CAATCACGACTGATTGGAATATAATATTGACAAAGGGAATGGGTAGAT TATATACCAAAAATAGTGAAGAATGTAGCTTAATAGTCTAGGGAGAGC AGGATAATCTTCGTTTTTGTTCATTAACGGCAATTGTATCCTGTTCGT CAATCAGTGTACATGATGTCCATTGCTCGAGATATGCATTAGTTCCGC ACTTCTAATCTTAAACCATTCTTCACTCTTCCAGGAATATTCTTCGCA TTCCTCCTTGTGAAATTATTCCATTCACCCGTGACGTTGATGAAAGAC GTGAAAAACCAAGACCTCAATTGGCAACTGTGGAAGTTCTCCTTTTGA AGCTGCACATCAGGTCTGCTTA

\section{AluSAT}

CAAGATAAGACATATTAAGTGTGGCATACGTTTTGTTGAAGCTCTCAC ATCCCACAAACATAATGCAAAAGTCATGAAAATTCTCTTGGCATCTGG TATAGATTTGCCAATGATGCTACTAAAAATGTATTCTGAGGAATACAT GGCGTTGAGTATTCGGCTCATGATATTTAAGTCTGTGGATGCTTTTTA CTGTCA

\section{RsaSAT}

TTGCTTTCATCGATCTCTATAAATCATTTTATGAAGGAATGTACCCTA AGTTTGGAGAACACGATATCGAAAACCCGAAGATATCAATTAATATCA ATCATGCAACAGACCTTGTAAGAGCTAAGTTTGCGATCGGTGCACTTA TCAAGAAGATAAATATTATA

\section{MboSAT}

AGGCGGAGTTAAAAAGACGCTAACTTCATAGTAAATTCTCTAGAAGAG ATACTGTACGTATAAAAATTGCTTCCAGTTATCTCAAAAACGTTTCCT ATCTCTGCACA

Fig. 4. Consensus sequences of the A. nerii satellite DNAs: EcoSAT, AluSAT, RsaSAT and MboSAT.

methylated-K9 histone $\mathrm{H} 3$ (fig. 5B-D). On the contrary, heterochromatin was not labeled after immuno-detection of methylated cytosines using mouse anti-5-methylcytosine antibodies (fig. 5E). In particular, the X chromosomes presented bright labeling limited to a large area close to the NOR-bearing telomere (as deduced by silver staining the same plate) (fig. 5F). According to previous analyses with $\mathrm{C}$-banding, these portions of the $\mathrm{X}$ chromosomes are euchromatic. A widespread occurrence of methylcytosine residues has been also observed in autosomes (fig. 5E).

\section{Discussion}

Even if aphid chromosomes are highly variable in number in view of their holocentric nature [Blackman, 1980; Blackman et al., 2000], our analysis of A. nerii metaphases evidenced the presence of 8 chromosomes which is in accordance with a previous estimation published by Khuda-Bukhsh and Pal [1985] confirming that aphids of the Aphis genus present a constant chromosome
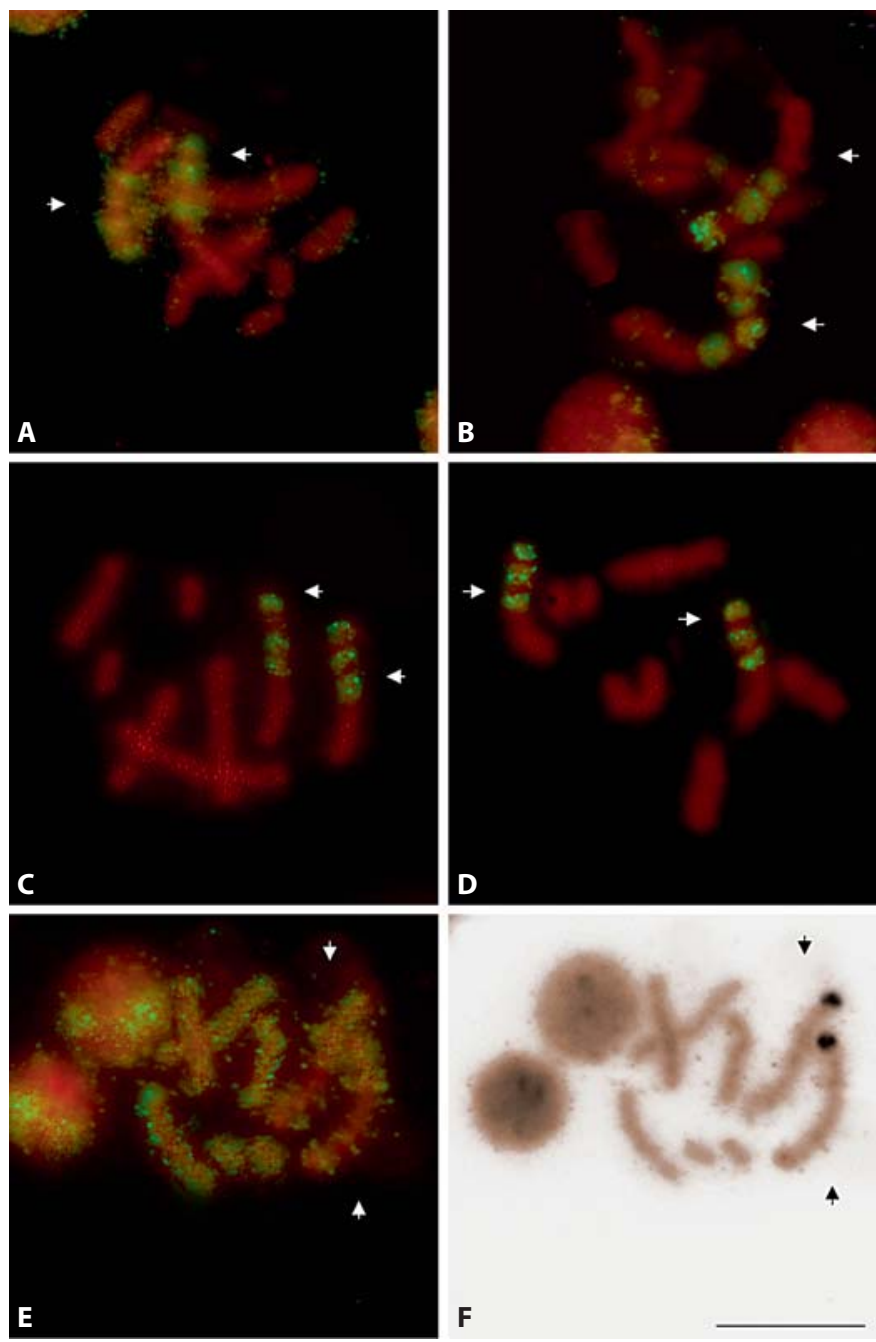

Fig. 5. A. nerii chromosomes (stained in red with propodium iodide) analyzed by immuno-staining with fluorescein-labeled antibodies against HP1 (A), monomethylated-K9 H3 histones (B), dimethylated-K9 $\mathrm{H} 3$ histones $(\mathbf{C})$, trimethylated-K9 $\mathrm{H} 3$ histones (D) and methylcytosine residues (E). In order to verify if the large band labeled after immuno-labeling with the anti-methylcytosine antibodies was near the NOR-bearing telomere, silver staining of the same plate has been done (F). Arrows indicate sex chromosomes. Bar corresponds to $10 \mu \mathrm{m}$.

number [Khuda-Bukhsh and Pal, 1985; Manicardi et al., 1998a, b; Criniti et al., 2005; Rivi et al., 2009] with only one exception, A. farinose [Blackman, 1980]. A. nerii also presents a stable chromosome number among different geographic populations, as demonstrated by the comparison of our data with that reported for A. nerii strains collected more than 20 years ago in India [Khuda-Bukhsh and Pal, 1985]. 
The production of males in A. nerii is noteworthy since this species has frequently been reported as being obligate parthenogenetic in Europe [e.g. Groeters and Dingle, 1989; Blackman and Eastop, 2006]. However, the occurrence of sexual generations of $A$. nerii has already been reported in the literature [Takada and Miyazaki, 1992] suggesting that this species could be a mosaic of holocyclic and obligate parthenogenetic populations, as reported in other aphid species [Blackman and Eastop, 2007].

C-banding and FISH utilizing $5 \mathrm{SrDNA}$ as a probe allow clear-cut identification of $\mathrm{X}$ and chromosomes 1 within the A. nerii complement thus improving the construction of a non-ambiguous karyotype. Indeed, holocentric chromosomes lack primary conscription, whereas attempts to identify homologue chromosomes only on the basis of their length can be misleading due to the phenomenon of allocyclia (see fig. $1 \mathrm{~N}$ and in particular fig. $1 \mathrm{M}$ in which the autosome pair 1 appears longer than the X chromosome),

Aphid X chromosomes present strong structural constraints since all the aphid species analysed to date have both a large load of heterochromatin at the telomeric and interstitial level and a single rDNA cluster located at one telomere (with the unique exceptions of Schoutedenia ralumensis and Maculachnus submacula that present autosomal NORs and Amphorophora idaei showing interstitial NORs at X chromosomes) [Mandrioli et al., 1999a, b; Manicardi et al., 2002]. This peculiar feature of X chromosomes could be related to the sex determination mechanism, which, in aphids, is generally based on the presence of females with $2 \mathrm{X}$ chromosomes (XX) and males with only one X chromosome (X0). Aphid males are produced by parthenogenetic females as a consequence of an $\mathrm{X}$ chromosome loss occurring in the course of a single maturation division [Blackman and Spence, 1996]. Indeed, the large blocks of heterochromatin may be involved in the delayed separation of X chromosomes during maturation of parthenogenetic aphid oocytes [Orlando, 1974; Blackman, 1987].

Furthermore, all the parthenogenetic eggs during prophase present a connection between the 2 NOR-bearing telomeres of the X chromosomes [Schrader, 1940; Orlando, 1974; Hales and Mitler, 1983; Blackman and Hales, 1986] that is quickly lost in females, whereas in male generating eggs the $\mathrm{X}$ chromosomes remain attached by sticky NORs and undergo a sort of non-canonic reductional division [Blackman and Hales, 1986]. At the end of this peculiar division the egg has one $\mathrm{X}$ chromosome only and is thereby determined as male. Aphid rDNA genes contain specific sequences that present high similarity with the consensus core region of human hypervariable minisatellites [Jeffreys et al., 1985] and with the $\chi$ sequence of Escherichia coli [Smith, 1983] that are involved in rDNA pairing, as also previously reported in D. melanogaster [Ault et al., 1982; Park and Yamamoto, 1995]. The occurrence of $\mathrm{X}$ chromosome pairing at NORs is supported by the frequent observation (also in A. nerii, data not shown) of intra- and inter-individual NOR heteromorphism, already reported in several aphid species [Mandrioli et al., 1999b, c] as the result of unequal crossing over between the $2 \mathrm{X}$ chromosomes.

NOR number and position have been reported as highly variable in insects and rDNA genes have been frequently found also (or mostly) on autosomes, including several species with multiple NORs [e.g. Postiglioni and Brum-Zorrilla, 1981, 1988; Juan et al., 1993; Mandrioli, 2002; Rocha et al., 2002; Loreto et al., 2008; Nguyen et al., 2010] making aphids an interesting exception among insects.

FISH experiments with $5 \mathrm{~S}$ rDNA probe revealed a single cluster located on autosome pair 1 indicating that $5 \mathrm{~S}$ localization is not linked to the other rDNA genes. This is not surprising considering that the absence of linkage between the $5 \mathrm{~S}$ and $28 \mathrm{~S}$ rDNA genes has already been reported in other insects [Drouin et al., 1992]. Up till now, $5 \mathrm{~S}$ rDNA localization in aphids has only been evaluated in A. pisum [Bizzaro et al., 2000], where the $5 S$ genes are located in 2 interstitial clusters on $\mathrm{X}$ chromosomes indicating that, contrarily to what is observed for the $28 \mathrm{~S}$ rDNA genes, $5 \mathrm{~S}$ gene localization in the aphid chromosomes is not under constraints.

The telomere of each chromosome consisted of the telomeric (TTAGG) $)_{n}$ repeat, as already reported not only in aphids, but also in other insects [Lorite et al., 2002; Robertson and Gordon, 2006; Frydrychová et al., 2004; Vítková et al., 2005]. In accordance with the stability of the chromosome number observed in A. nerii, no interstitial (TTAGG) $)_{\mathrm{n}}$ sequence was detected. However, more sensitive FISH procedures would have to be used in order to verify if no chromosome fusion occurred in A. nerii, or alternatively, if fusions occurred in the past so that interstitial telomeric sequences have been progressively eroded.

Several satellite DNAs have been isolated in organisms possessing monocentric chromosomes, whereas only a few studies were published on highly repeated DNAs in invertebrates with holocentric chromosomes with the exception of nematodes [Grenier et al., 1997]. To date, satellite DNAs have been isolated in only 2 aphid species, $M y$ - 
zus persicae [Spence et al., 1998; Mandrioli et al., 1999a] and Megoura viciae [Bizzaro et al., 1996], making difficult the identification of common properties of aphid satellite DNAs.

The sequences of the $A$. nerii satDNAs were highly conserved and this could be due to processes of 'concerted evolution' determined by molecular drive [Dover et al., 1982; Dover and Tautz, 1986] or to the presence of constraints due to the interaction of satDNAs with specific proteins involved in heterochromatin formation [Talbert et al., 2004; Palomeque and Lorite, 2008]. Sequence variability of satDNAs depends on the ratio between mutation and homogenization/fixation rates [Dover, 2002] and in insects falls in the range $1-13 \%$ even if very similar satDNAs are more frequent than variable ones [LopezLeon et al., 1995; Mandrioli et al., 1999a; Landais et al., 2000].

The 4 sequenced satDNAs possess a conserved length and this feature was related to a possible role of the satellite DNAs in the nucleosome phasing necessary during the process of heterochromatin condensation [Henikoff et al., 2001]. At the same time, however, the absence of internal repeats in all the $A$. nerii satDNAs could also explain this constancy since internal direct and inverted repeats are correlated to satellite DNA rearrangements [Palomeque and Lorite, 2008].

The presence of a high AT content is a general feature of satellite DNAs identified in A. nerii and it is consistent with the AT richness reported in satDNA of several other animals [Palomeque and Lorite, 2008]. Besides this, the high AT content of the A. nerii satDNAs fits our cytological data which showed their localization into DAPI fluorescent $\mathrm{C}$ bands after FISH. Indeed, in situ hybridization showed that they co-localize with heterochromatic bands of the $\mathrm{X}$ chromosomes, whereas no hybridization signals have been observed on autosomes. This distribution is similar to that observed in M. persicae and M. viciae, where the satellite DNAs labeled only intercalary heterochromatic bands of the $2 \mathrm{X}$ chromosomes [Bizzaro et al., 1996; Mandrioli et al., 1999a].

The transcription of insect satDNAs has been studied in a few species and just some of them present RNAs related to these repetitive DNA. RNAs related to the A. nerii satDNAs have been searched by RT-PCR without positive results. However, in insects satDNA transcription is related to cell type, developmental stage and sex so that it may not be so easy to detect the transcripts [Palomeque and Lorite, 2008]. In addition, at least in D. melanogaster [Palomeque and Lorite, 2008], satellite DNA-related transcripts consist of small RNAs that cannot be detected by
RT-PCR so that an exhaustive assessment of satellite transcription in aphids is worthy of further investigations.

As a whole, $A$. nerii satDNAs present several features that are typical of the other satellite DNAs isolated in the aphids since (i) they present a high degree of similarity among the sequenced repeats both in length and sequence (the percentage of similarity is greater than 90\%), (ii) they show a high AT content (at least 60\%), (iii) they contain an internal region with a high curvature propensity and localize in AT-rich heterochromatic regions of the X chromosomes.

These data suggest that, in holocentric chromosomes also, constitutive heterochromatin is principally made of satellite DNAs in agreement with data repeatedly described in monocentric chromosomes [John and Miklos, 1979; John, 1988].

According to previous studies in different animals, including the holocentric chromosomes of the coccid Planococcus citri [Cowell et al., 2002; Bongiorni and Prantera, 2003; Kourmouli et al., 2004], A. nerii constitutive heterochromatin is enriched in both bi- and trimethylated $\mathrm{H} 3$ histones and HP1 proteins. On the contrary, data about the localization of $\mathrm{H} 3 \mathrm{~K} 9 \mathrm{mel}$ are in contrast with the high-resolution profiling of histone methylations in the human genome which revealed that the higher H3K9mel levels were mainly detected near the $5^{\prime}$ end of actively transcribed genes [Barski et al., 2007]. These results, previously observed in the aphid Acyrthosiphon pisum [Mandrioli and Borsatti, 2007], strongly resemble those reported for DNA methylation that is present both in silent and actively transcribed genes, and this double function is due to the different effector proteins that interact with DNA methylation at the promoter (where DNA methylation suppresses transcription) [Mandrioli, 2004] and inside the coding regions (where DNA methylation suppresses the transcriptional background of active genes) [Mandrioli, 2004]. Similarly, H3K9mel could be involved both in silencing and activation of transcription through a different location and the recruitment of different proteins. Our cytogenetic data do not allow us to give a proper reply to this question since immunolabelling did not furnish information at a molecular level but at a chromosomal level only. Further studies could be therefore prompted by our results.

Our experiments showed that $A$. nerii heterochromatin lacks DNA methylation since methylated cytosine residues are widespread in euchromatic chromosomal regions. This is very interesting since the results reported 
in A. pisum and in the coccid Planococcus citri [Bongiorni et al., 1999] indicate that insect heterochromatin is poor in terms of DNA methylation, whereas euchromatin can be highly methylated. Hence, taken together with data in other insects and in the nematode Caenorhabditis elegans [Mandrioli, 2004; Mandrioli and Borsatti, 2006, 2007], it emerges that in invertebrates, contrarily to what is reported in plants and mammals [Mandrioli and Borsatti, 2005], heterochromatin is assembled and condensed without any involvement of DNA methylation.

This suggestion, even if apparently surprising in comparison to the canonical view of DNA methylation, is not unexpected in insects where it has been previously suggested that methylated genes can be actively transcribed [Field et al., 2004; Mandrioli, 2004; Walsh et al., 2010]. In particular, it has been suggested that DNA methylation has been recruited in insects not for silencing gene transcription, but to avoid transcription initiation from spurious promoters [Field et al., 2004; Mandrioli, 2004]. On the basis of this presumed function, DNA methylation in insects should be present in euchromatin rather than in heterochromatin, a hypothesis confirmed in the case of A. nerii.

In view of such a scenario, it could be very intriguing to study the expression of genes coding for DNA methyltransferase and histone methyl-transferase in the aphid genome in order to better understand the roles played by these epigenetic processes and their interactions. The availability of the whole sequenced $A$. pisum genome (which has been recently annotated) will surely provide important replies to these questions, thereby making aphids good models for studying the evolution of histone and DNA methylation in insects.

\section{Acknowledgements}

We are greatly indebted to Rebecca Kellum for sending us the mouse anti-Drosophila HPla antibody. This work is supported by the grant 'F.A.R.' from the University of Modena and Reggio Emilia (M.M.) and by the grant 'Experimental approach to the study of evolution' from the Department of Animal Biology of the University of Modena and Reggio Emilia (M.M.).

\section{References}

-Ault JG, Lin HPP, Church K: Meiosis in Drosophila melanogaster. Chromosoma 86:309-317 (1982).

- Barski A, Cuddapah S, Cui K, Roh TY, Schones $\mathrm{DE}$, et al: High-resolution profiling of histone methylations in the human genome. Cell 129:823-837 (2007).

-Bizzaro D, Manicardi GC, Bianchi U: Chromosomal localization of a highly repeated EcoRI DNA fragment in Megoura viciae (Homoptera, Aphididae) by nick translation and FISH. Chromosome Res 4:392-396 (1996).

-Bizzaro D, Mandrioli M, Zanotti M, Giusti M, Manicardi GC: Chromosome analysis and molecular characterization of highly repeated DNAs in the aphid Acyrthosiphon pisum (Aphididae, Hemiptera). Genetica 108:197202 (2000).

Blackman RL: Chromosome numbers in the Aphididae and their taxonomic significance. Syst Entomol 5:7-25 (1980).

Blackman RL: Reproduction, cytogenetics and development, in Minsk AK, Harrewijn P (eds): Aphids: Their Biology, Natural Enemies and Control, Vol A, pp 163-195 (Elsevier, Amsterdam 1987).

Blackman RL, Eastop VF: Aphids on the World's Herbaceous Plants and Shrubs (Wiley, Chicester 2006).

Blackman RL, Eastop VF: Aphids as Crop Pests. van Emden HF, Harrington R (eds) (CABI, London 2007).
Blackman RL, Hales DF: Behaviour of the X chromosomes during growth and maturation of parthenogenetic eggs of Amphorophora tuberculata (Homoptera, Aphididae) in relation to sex determination. Chromosoma 94:59-64 (1986).

Blackman RL, Spence JM: Ribosomal DNA is frequently concentrated on only one X chromosome in permanently apomiptic aphids, but this does not inhibit male determination. Chromosome Res 4:314-320 (1996).

Blackman RL, Spence JM, Normark BB: High diversity of structurally heterozygous karyotypes and rDNA arrays in parthenogenetic aphids of the genus Trama. Heredity 84:254260 (2000).

Bongiorni S, Prantera G: Imprinted facultative heterochromatization in mealybugs. Genetica 117:271-279 (2003).

Bongiorni S, Cintio O, Prantera G: The relationship between DNA methylation and chromosome imprinting in the Coccid Planococcus citri. Genetics 151:1471-1478 (1999).

Bongiorni S, Mazzuoli M, Masci S, Prantera G: Facultative heterochromatinization in parahaploid male mealybugs: involvement of a heterochromatin-associated protein. Development 128:3809-3817 (2001).
Cowell IG, Aucott R, Mahadevaiah SK, Burgoyne PS, Huskisson N, et al: Heterochromatin, HP1 and methylation at lysine 9 of histone $\mathrm{H} 3$ in animals. Chromosoma 111:22-36 (2002).

Crema R: Egg viability and sex determination in Megoura viciae (Homoptera, Aphididae). Entomol. Experiment Appl 26:152-156 (1979).

Criniti A, Simonazzi G, Cassanelli S, Ferrari M, Bizzaro D, Manicardi GC: X-linked heterochromatin distribution in the holocentric chromosomes of the green apple aphid Aphis pomi. Genetica 124:93-98 (2005).

Criniti A, Simonazzi G, Cassanelli S, Ferrari M, Bizzaro D, Manicardi GC: Distribution of heterochromatin and rDNA on the holocentric chromosomes of the aphids Dysaphis plantaginea and Melanaphis pyraria (Hemiptera, Aphididae). Eur J Entomol 106:153157 (2009).

Dernburg AF: Here, there and everywhere. Kinetochore function on holocentric chromosomes. J Cell Biol 153:33-38 (2001).

Donlon TA, Magenis RE: Methyl green is a substitute for distamycin $\mathrm{A}$ in the formation of distamycin A/DAPI C-bands. Hum Genet 65:144-146 (1983).

Dover G: Molecular drive. Trends Genet 18:587589 (2002) 
Dover GA, Tautz D: Conversion and divergence in multigene families: alternatives to selection and drift. Philos Trans R Soc Lond Ser B 312:275-289 (1986).

Dover GA, Brown S, Coen E, Dallas J, Strachan $\mathrm{T}$, Trick M: The dynamics of genome evolution and species differentiation, in Dover GA, Flavell RB (eds): Genome Evolution, pp 343-372 (Academic Press, London 1982).

Drouin G, Sèvigny JM, McLaren IA, Hofman JD, Doolittle WF: Variable arrangements of $5 \mathrm{~S}$ ribosomal DNA repeats of arthropods. Mol Biol Evol 9:826-835 (1992).

-Field LM, Lyko F, Mandrioli M, Prantera G: DNA methylation in insects. Insect Mol Biol 13:109-217 (2004).

-Frydrychová R, Grossmann P, Trubac P, Vítková M, Marec F: Phylogenetic distribution of TTAGG telomeric repeats in insects. Genome 47:163-178 (2004).

-Gabrielian G, Simoncsits A, Pongor S: Distribution of bending propensity in DNA sequences. FEBS Lett 393:124-130 (1996).

Geiduschek EP, Tocchini-Valentini GP: Transcription by RNA polymerase III. Annu Rev Biochem 57:873-914 (1988).

- Grenier E, Castagnone-Sereno P, Abad P: Satellite DNA sequences as taxonomic markers in nematodes of agronomic interest. Parasitol Today 13:398-401 (1997).

Groeters FR, Dingle H: The cost of being able to fly in the milkweed-oleander aphid, Aphis nerii (Homoptera: Aphididae). Evolutionary Ecol 3:313-326 (1989).

-Hales DF, Mitler TE: Precocene causes male determination in the aphid Myzus persicae. J Insect Physiol 29:819-823 (1983).

Henikoff S, Ahmad K, Malik HS: The centromere paradox: stable inheritance with rapidly evolving DNA. Science 293:1098-1102 (2001).

- Huang DW, Fanti L, Pak DTS, Botchan MR, Pimpinelli S, Kellum R: Distinct cytoplasmic and nuclear fractions of Drosophila heterochromatin protein 1: their phosphorylation levels and associations with origin recognition complex proteins. J Cell Biol 142:307318 (1998).

Hughes-Schrader S, Schrader F: The kinetochore of the Hemiptera. Chromosoma 12: 327-350 (1961).

-Ijdo JW, Wells RA, Baldini A, Reeders ST: Improved telomere detection using a telomere repeat probe $(\text { TTAGGG) })_{\mathrm{n}}$ generated by PCR. Nucleic Acids Res 19:4780 (1991).

-Jeffreys AJ, Wilson V, Thein SL: Hypervariable minisatellite regions in human DNA. Nature 314:67-73 (1985).

John B: The biology of heterochromatin, in Verna RS (ed): Heterochromatin: Molecular and Structural Aspects, pp 1-147 (Cambridge University Press, Cambridge 1988).

John B, Miklos GLG: Functional aspects of satellite DNA and heterochromatin. Int Rev Cytol 58:111-114 (1979).
Juan C, Pons J, Petitpierre E: Localization of tandemly repeated DNA sequences in beetle chromosomes by fluorescent in situ hybridization. Chromosome Res 1:167-174 (1993).

Kourmouli N, Jeppesen P, Mahadevhaiah S, Burgoyne $\mathrm{P}, \mathrm{Wu} \mathrm{R}$, et al: Heterochromatin and tri-methylated lysine 20 of histone $\mathrm{H} 4$ in animals. J Cell Sci 117:2491-2501 (2004).

Khuda-Bukhsh AR, Pal NB: Cytogenetic studies on aphids (Homoptera: Aphididae) from India: Karyomorphology of eight species of Aphis. Entomol 10:171-177 (1985).

Landais I, Chavigny P, Castagnone C, Pizzol J, Abad P, Vanlerberghe-Masutti F: Characterization of a highly conserved satellite DNA from the parasitoid wasp Trichogramma brassicae. Gene 255:65-73 (2000).

Lopez-Leon MD, Vazquez P, Hewitt GM, Camacho JP: Cloning and sequence analysis of an extremely homogeneous tandemly repeated DNA in the grasshopper Eyprepocnemis plorans. Heredity 75:370-375 (1995).

Loreto V, Cabrero J, López-León MD, Camacho JP, de Souza MJ: Comparative analysis of rDNA location in five Neotropical gomphocerine grasshopper species. Genetica 132: 95-101 (2008).

Lorite P, Carrillo JA, Palomeque T: Conservation of (TTAGG)n telomeric sequences among ants (Hymenoptera, Formicidae). J Hered 93: 282-285 (2002).

Mandrioli M: Cytogenetic characterization of telomeres in the holocentric chromosomes of the lepidopteran Mamestra brassicae. Chromosome Res 9:279-286 (2002).

Mandrioli M: Epigenetic tinkering and evolution: is there any continuity in the functional role of cytosine methylation from invertebrates to vertebrates? Cell Mol Life Sci 61: 2425-2427 (2004).

Mandrioli M, Borsatti F: Histone methylation and DNA methylation: a missed pas de deux in invertebrates? Inv Surv J 2:159-161 (2005)

Mandrioli M, Borsatti F: DNA methylation of fly genes and transposons. Cell Mol Life Sci 63: 1963-1966 (2006)

Mandrioli M, Borsatti F: Analysis of heterochromatic epigenetic markers in the holocentric chromosomes of the aphid Acyrthosiphon pisum. Chromosome Res 15:1015-1022 (2007).

Mandrioli M, Bizzaro D, Gionghi D, Bassoli L, Manicardi GC, Bianchi U: Molecular cytogenetic characterization of a highly repeated DNA sequence in the peach potato aphid Myzus persicae. Chromosoma 108:436-442 (1999a).

-Mandrioli M, Bizzaro D, Giusti M, Manicardi GC, Bianchi U: The role of rDNA genes in $\mathrm{X}$ chromosomes association in the aphid Acyrthosiphon pisum. Genome 42:381-386 (1999b).
Mandrioli M, Bizzaro D, Giusti M, Gionghi, D, Manicardi GC, Bianchi U: Cytogenetic and molecular characterization of a highly repeated DNA sequence in the peach potato aphid Myzus persicae. Chromosoma 108: 436-442 (1999c).

-Manicardi GC, Gautam DC, Bizzaro D, Guicciardi E, Bonvicini Pagliai AM, Bianchi U: Chromosome banding in Aphids: G, C, AluI, and HaeIII banding patterns in Megoura viciae (Homoptera, Aphididae). Genome 34: 661-665 (1991).

Manicardi GC, Mandrioli M, Bizzaro D, Bianchi $\mathrm{U}$ : Silver staining as a new banding technique to identify aphid chromosomes. Chromosome Res 6:55-57 (1998a).

-Manicardi GC, Mandrioli M, Bizzaro D, Bianchi U: Patterns of DNase I sensitivity in the holocentric chromosomes of the aphid Megoura viciae. Genome 41:169-172 (1998b).

Manicardi GC, Mandrioli M, Bizzaro D, Bianchi $\mathrm{U}$ : Cytogenetic and molecular analysis of heterochromatic areas in the holocentric chromosomes of different aphid species, in Sobti RG, Obe G, Athwal RS (eds): Chromosome Structure and Function, pp 47-56 (Kluwer Academic Publishers, Dordrecht 2002).

Nguyen P, Sahara K, Yoshido A, Marec F: Evolutionary dynamics of rDNA clusters on chromosomes of moths and butterflies (Lepidoptera). Genetica 138:343-354 (2010).

Orlando E: Sex determination in Megoura viciae Bukton (Homoptera, Aphididae). Monit Zool 8:61-70 (1974).

- Palomeque T, Lorite P: Satellite DNA in insects: a review. Heredity 100:564-573 (2008).

- Park HS, Yamamoto MT: The centric region of the $\mathrm{X}$ chromosome rDNA functions in male meiotic pairing in Drosophila melanogaster. Chromosoma 103:700-707 (1995).

Pfarr W, Webersinke G, Paar C, Wechselberger C: Immunodetection of 5'methylcytosine on Giemsa-stained chromosomes. Biotechniques 38:527-530 (2005).

Postiglioni A, Brum-Zorrilla N: Localizacion de regiones organizadoras nucleolares (NORs) en otra especie con sistema sexual Xyp Calligrapha polyspila (Coleoptera, Chrysomelidae, Chrysomelinae). Resrimenes Comun Jornadas Cienc Nat Montevideo 2 (1981).

Postiglioni A, Brum-Zorrilla N: Non-relationship between nucleolus and sex chromosome $\mathrm{XY}$ in Chelymorpha variubilis Boheman (Coleoptera: Chrysomelidae). Genetica 77: 137-141 (1988).

Rakauskas R: What is the (aphid) species? in Nieto Nafria JM, Dixon AGF (eds): Aphids in Natural and Managed Ecosystems, pp 451455 (Universidad de Leon, Secretariado de Publicaciones, Lein 1998).

-Rivi M, Cassanelli S, Mazzoni E, Bizzaro D, Manicardi GC: Heterochromatin and rDNA localization on the holocentric chromosomes of black bean aphid, Aphis fabae Scop. (Hemipetra, Aphididae). Caryologia 62:341346 (2009). 
Robertson HM, Gordon KH: Canonical TTAGG-repeat telomeres and telomerase in the honey bee, Apis mellifera. Genome Res 16:1345-1351 (2006).

- Rocha MP, Pompolo AS, Dergam JA, Fernandes A, De Oliverira Campos LA: DNA characterization and karyotypic evolution in the bee genus Melipona (Hymenoptera, Meliponini). Hereditas 136:19-27 (2002).

Schrader F: Touch and go pairing in chromosomes. Proc Natl Acad Sci USA 26:634-636 (1940).

-Schweizer D: Reverse fluorescent chromosome banding with chromomycin and DAPI. Chromosoma 58:307-324 (1976).

Smith RG: Chi hotspots of generalized recombination. Cell 34:709-710 (1983).
Spence JM, Blackman RL, Testa JM, Ready PD: A 169-base pair tandem repeat DNA marker for subtelomeric heterochromatin rearrangements in aphids of the Myzus persicae group. Chromosome Res 6:167-175 (1998).

Sumner AT: A simple technique for demonstrating centromeric heterochromatin. Exp Cell Res 75:304-306 (1972).

- Sumner AT, Taggart MH, Mezzanotte R, Ferrucci L: Patterns of digestion of human chromosomes by restriction endonucleases demonstrated by in situ nick translation. Histochem J 22:639-652 (1990).

Takada H, Miyazaki M: Occurrence of sexuales of Aphis nerii B De F (Homoptera, Aphididae) in Japan. Appl Entomol Zool 27:117-124 (1992).
Talbert PB, Bryson TD, Henikoff S: Adaptive evolution of centromere proteins in plants and animals. J Biol 3:18 (2004).

Vítková M, Král J, Traut W, Zrzavý J, Marec F: The evolutionary origin of insect telomeric repeats, (TTAGG) ${ }_{n}$. Chromosome Res 13: 145-156 (2005).

Walsh TK, Brisson JA, Robertson HM, Gordon K, Jaubert-Possamai S, et al: A functional DNA methylation system in the pea aphid Acyrthosiphon pisum. Insect Mol Biol 19: 215-228 (2010).

Wrensch DL, Ketheley JB, Norton RA: Cytogenetics of holokinetic chromosomes and inverted meiosis: keys to the evolutionary success of mites with generalization on eukaryotes, in Houck MA (ed): Mites. Ecological and Evolutionary Analysis of Life-History Patterns, pp 282-343 (Chapman and Hall, New York 1994). 